\title{
SEGURANÇA JURÍDICA E A TÉCNICA DE DISTINÇÃO E SUPERAÇÃO DOS PRECEDENTES JUDICIAIS
}

\author{
LEGAL CERTAINTY AND THE TECHNIQUE OF DISTINCTION AND \\ OVERCOMING OF JUDICIAL PRECEDENTS
}

\author{
Délio Mota de Oliveira Júnior ${ }^{1}$
}

\begin{abstract}
RESUMO
O objeto deste estudo é a análise do princípio da segurança jurídica na atual tendência de padronização decisória, que vem ocorrendo no processo civil brasileiro, na medida em que as recentes reformas legislativas atribuem expressa força vinculante às decisões judiciais, revelando a tendência de valorização crescente do uso de julgados como se fossem os precedentes do common law, em clara convergência das tradições civil law e common law. $\mathrm{O}$ artigo aborda a necessidade de que tais reformas processuais criem institutos e mecanismos que, apesar de prever a aplicação vinculativa e/ou impor a observância do precedente judicial, possibilite técnica de distinção dos precedentes, bem como de sua superação. Analisa-se a necessidade de assegurar a atribuição dos efeitos prospectivos, no caso da superação de um entendimento consolidado, em atenção ao princípio da segurança jurídica, diante da confiança justificada que existia em relação ao precedente.
\end{abstract}

Palavras-chave: Processo civil, Segurança jurídica, Padronização decisória, Jurisdição constitucional

\begin{abstract}
The object of this study is the analysis of the principle of legal certainty in the current trend of decision standardization, which has been taking place in the Brazilian civil procedure as recent legislative reforms attribute express binding force to judicial decisions, revealing the growing trend of using judgments as if they were the precedents of the common law, in a clear convergence of the civil law and the common law traditions. The article discusses the need for such procedural reforms to create institutions and mechanisms that, despite predicting the binding application and/or enforcing the observance of the judicial precedent, enables a technique of distinction of the precedents, as well as their overcoming. It analyzes the need to ensure the attribution of prospective effects, in the case of overcoming a consolidated understanding, in regard to the principle of legal certainty, given the justifiable confidence that existed in relation to the precedent.
\end{abstract}

Keywords: Civil procedure, Legal certainty, Decision standardization, Constitutional jurisdiction

\footnotetext{
${ }^{1}$ Mestrado em Direito Processual Civil pela Universidade Federal de Minas Gerais - UFMG, Minas Gerais, (Brasil). Professor pela Faculdade de Direito Milton Campos, Minas Gerais, (Brasil). E-mail: deliomtjr@gmail.com
} 


\section{INTRODUÇÃO: A TENDÊNCIA DE PADRONIZAÇÃO DECISÓRIA}

A partir da década de 1970 e, com maior dimensão, principalmente após a Constituição da República de 1988, diante da garantia de acesso à Justiça (art. 5º XXXV) e da previsão de uma série de políticas públicas de inclusão, o processo civil começa a ser dimensionado não apenas para resolver conflitos individuais e privados; surge à visão do processo como instrumento para se alcançar os direitos fundamentais e o interesse público (ativismo judicial) ${ }^{2}$ 3 .

Boaventura de Souza Santos (2007, p. 20) destaca que "a constitucionalização de um conjunto tão extenso de direitos sem o respaldo de políticas públicas e sociais consolidadas, torna difícil a sua efetivação, mas não é menos verdade que esse catálogo amplo de direitos abre espaço para uma maior intervenção judicial a partir do controle da constitucionalidade do direito ordinário".

A busca pela consolidação do Estado Democrático de Direito, assegurado pela Constituição da República de 1988, com o reconhecimento de normatividade e efetividade das garantias fundamentais, promoveu a constitucionalização do Direito e a judicialização das relações sociais e políticas ${ }^{4}$.

\footnotetext{
2 NUNES, Dierle. "Processualismo constitucional democrático e o dimensionamento de técnicas para a litigiosidade repetitiva: a litigância de interesse público e as tendências 'não compreendidas' de padronização decisória". Revista de Processo, vol. 199, set. 2011, pp. 41-82, esp. p. 45.

${ }^{3}$ Luís Roberto Barroso afirma que, no Brasil, "a judicialização decorre, sobretudo, de dois fatores: o modelo de constitucionalização abrangente e analítica adotado; e o sistema de controle de constitucionalidade vigente entre nós, que combina a matriz americana - em que todo juiz e tribunal pode pronunciar a invalidade de uma norma no caso concreto - e a matriz européia, que admite ações diretas ajuizáveis perante a corte constitucional. Nesse segundo caso, a validade constitucional de leis e atos normativos é discutida em tese, perante o Supremo Tribunal Federal, fora de uma situação concreta de litígio. Essa fórmula maximizada no sistema brasileiro pela admissão de uma variedade de ações diretas e pela previsão constitucional de amplo direito de propositura. Nesse contexto, a judicialização constitui um fato inelutável, uma circunstância decorrente do desenho institucional vigente, e não uma opção política do Judiciário. Juízes e tribunais, uma vez provocados pela via processual adequada, não têm a alternativa de se pronunciarem ou não sobre a questão. Todavia, o modo como venham a exercer essa competência é que vai determinar a existência ou não de ativismo judicial." (BARROSO, Luis Roberto. "Constituição, Democracia e Supremacia Judicial: Direito e política no Brasil contemporâneo". As Novas Faces do Ativismo Judicial. Coord: FELLET, André Luiz Fernandes; PAULA, Daniel Giotti de; NOVELINO, Marcelo. Salvador: Editora JusPodivm. 2013, p. 231-232).

${ }^{4}$ BARROSO, Luís Roberto. "Elementos para a construção de um Direito Jurisprudencial”. In MELLO, Patrícia Perrone Campos. Precedentes: $O$ desenvolvimento judicial do direito no constitucionalismo contemporâneo. Rio de Janeiro: Renovar, 2008.
} 
Neste contexto, houve significativo crescimento do número de processos submetidos ao Poder Judiciário, ampliando-se a litigiosidade coletiva e repetitiva ${ }^{6}{ }^{7}$. Entretanto, paralelamente a tal fenômeno, diante das deficiências infraestruturais dos órgãos jurisdicionais, restou evidenciada a morosidade na prestação da tutela jurisdicional efetiva, o que repercutiu em descrédito do Poder Judiciário, debilitando a consolidação do Estado Democrático de Direito $^{89}$.

\begin{abstract}
5 "Quando analisamos a utilização corrente da judicialização em nosso país para implementação de direitos fundamentais não podemos despresar a situação de que tal fenômeno representa uma consequencia de um problema mais grave: a crise das instituições de nosso país. Vemos uma democracia representativa em crise e um Parlamento sem agenda. Um Executivo que não promove as políticas públicas necessárias para garantia dos direitos fundamentais, em verdade, as políticas públicas deste último se preocupam apenas com a tentativa de redivisão de renda, mas não com a consecução de todo o projeto constitucional de 1988 e de políticas de consolidação de direitos fundamentais." (THEODORO JÚNIOR, Humberto; NUNES, Dierle José Coelho; BAHIA, Alexandre Gustavo Melo. "Breves considerações da politização do judiciário e do panorama de aplicação no direito brasileiro - Análise da convergência entre o civil law e o common law e dos problemas da padronização decisória". Revista de Processo, vol. 189, 2010, p. 9-52).
\end{abstract}

${ }^{6}$ JAYME, Fernando Gonzaga; FERNANDES, Tereza de Assis. "Julgamento Liminar do Pedido - análise dos critérios de aplicação e inevitável crítica em relação a sua disciplina no Projeto de Novo Cógigo Civil". Coord: FREIRE, Alexandre, et al. Novas Tendências do processo Civil: Estudo sobre o Projeto de Novo Código de Processo Civil. Salvador: Editora JusPodivm, 2013, p. 146.

${ }^{7}$ Dierle Nunes argumenta que, "na atualidade, esta litigiosidade [individual] não se mostra como a mais preocupante para a aplicação de direitos e $\mathrm{m}$ face do fato de que após a Constituição cidadã de 1988, e da assunção efetiva de garantias de acesso à justiça (art. 5. ${ }^{\circ}, \mathrm{XXXV}$, da CF/1988) e do devido processo legal (art. 5. ${ }^{\circ}$, LIV, da CF/1988), o processo se tornou uma garantia do cidadão para viabilizar a obtenção de direitos (fundamentais) e permitir que a litigiosidade coletiva e serial (repetitiva), especialmente a litigância de interesse público (PIL), fosse submetida ao Poder Judiciário." (NUNES, Dierle. "Processualismo constitucional democrático e o dimensionamento de técnicas para a litigiosidade repetitiva: a litigância de interesse público e as tendências 'não compreendidas' de padronização decisória". Revista de Processo. São Paulo: RT, vol. 199, set. 2011, p. 41-82, esp. p. 45).

${ }^{8}$ JAYME, Fernando Gonzaga. "Necessitamos de um Novo Código de Processo Civil?". In: MACHADO, Felipe; CATTONI DE OliVEIRA, Marcelo Andrade (Coord.). Constituição e Processo: uma análise hermenêutica da (re)construção dos códigos. Belo Horizonte: Fórum, 2012, p. 135-150.

${ }^{9}$ Eis a pesquisa do Conselho Nacional de Justiça - CNJ acerca da taxa de congestionamentos dos processos no Brasil: "O Brasil é o país que apresenta maior taxa de congestionamento, 70\%, seguido de Bósnia e Herzegovina e Portugal, com 68 e 67\%, respectivamente. Observa-se elevada diferença entre a taxa mais alta, de $70 \%$, e a mais baixa, de 3\%, referente à Federação Russa. Assim como a maior taxa de congestionamento, o Brasil também apresenta o maior número de advogados por magistrado, seguido por Itália e Malta, com 25 e 33 advogados, respectivamente (...). Como a elevada proporção de advogados em relação a magistrados pode indicar que existe elevada propensão ao litígio e relativa incapacidade de fazer frente a essa tendência, analisou- se o coeficiente de correlação entre a proporção de advogados por magistrados e a taxa de congestionamento. Obteve-se como resultado um valor de $61,8 \%$. Isso significa que há relação alta e significativa entre essas duas variáveis. Ou seja, quanto maior o número de advogados por magistrado, maior tende a ser a taxa de congestionamento desses países. (...) O Brasil possui a terceira maior produtividade quando comparado aos países da Europa. Não obstante, contrariamente à Dinamarca, essa produtividade é ainda inferior à carga de trabalho, e isso se reflete em uma taxa de congestionamento alta. Pode-se dizer que o Brasil está em posição intermediária entre a Bósnia e Herzegovina e a Dinamarca." (BRASIL. Conselho Nacional de Justiça - CNJ. Estudo Comparado Sobre Recursos, Litigiosidade e Produtividade: a prestação jurisdicional no contexto internacional. Brasilia: CNJ, 2011). 
Com o intuito de reduzir a morosidade do Poder Judiciário (garantia da duração razoável do processo), a imprevisibilidade das decisões e a instabilidade da jurisprudência (garantia da segurança jurídica e da isonomia), bem como evitar a transformação dos Tribunais Superiores em instância revisionais, o legislador vem promovendo diversas e sucessivas reformas processuais, de modo a valorizar os efeitos vinculantes e/ou impor a observância aos precedentes judiciais, em nítido processo de padronização decisória.

Antes do advento da Emenda Constitucional no 45/2004, apenas as decisões judiciais decorrentes do controle concentrado de constitucionalidade possuíam efeitos vinculantes e eficácia erga omnes, conforme redação dada pela Emenda Constitucional nº 03/1993 ao §2º do artigo 102 da Constituição da República de $1988^{10}$ 11. Com a "Reforma do Judiciário", através da Emenda Constitucional no 45/2004, criou-se institutos e mecanismos, como a súmula vinculante e a repercussão geral no recurso extraordinário, que revelam o propósito do legislador constituinte derivado de atribuir efeito vinculante aos enunciados de súmula e padronizar o entendimento da jurisprudência do Supremo Tribunal Federal.

Os enunciados de súmula (sem força vinculante) foram criados por sugestão do Ministro Victor Nunes Leal $^{12}{ }^{13}$, com a finalidade de facilitar o trabalho dos juízes e dos advogados, na medida em que o entendimento dominante da jurisprudência do Tribunal estaria em pequenos textos sumarizados, dispensando a pesquisa nas decisões anteriores acerca de determinada questão de direito. Acreditava-se que tais enunciados preveniriam recursos inúteis às partes, bem como pacificaria eventual divergência de interpretação da questão de direito. Contudo, o número de recursos não diminuiu e não se resolveu o "problema" das divergências de interpretação; ao contrário, começou a serem dadas também interpretações diversas aos próprios textos sumarizados ${ }^{14} 15$.

Ainda assim, na Emenda Constitucional n $n^{\circ}$ 45/2004, criou-se a possibilidade do Plenário do Supremo Tribunal Federal editar enunciados de súmulas vinculantes (art. 103-A da Constituição da República de 1988 e, posteriormente, também regulada pela Lei $\mathrm{n}^{\circ}$ 11.417/2006), que vinculam os demais órgãos do Poder Judiciário e a administração pública direta e indireta, nas esferas federal, estadual e municipal ${ }^{16}$, ao entendimento da Corte Suprema ${ }^{17}$. 


\begin{abstract}
${ }^{10}$ Redação do $\S 2^{\circ}$, do artigo 102, da Constituição da República de 1988, constante da Emenda Constitucional n ${ }^{\circ}$ 03/1993: “Art. 102. (...) § 2. ${ }^{\circ}$ As decisões definitivas de mérito, proferidas pelo Supremo Tribunal Federal, nas ações declaratórias de constitucionalidade de lei ou ato normativo federal, produzirão eficácia contra todos e efeito vinculante, relativamente aos demais órgãos do Poder Judiciário e ao Poder Executivo."
\end{abstract}

${ }^{11}$ Marcelo Alves Dias de Souza pontua que "a Contituição Federal, na redação dada ao seu §2 do art. 102 pela Emenda Constitucional 03/93, era expressa ao atribuir à ação declaratória de constitucionalidade, além de eficácia erga omnes, o efeito vinculante. Entretanto, nada dizia em relação à ação direta de inconstitucionalidade. Criou-se, então, à época, o debate: a decisão na ação direta de inconstitucionalidade possui ou não efeito vinculante? Havia quem entendesse que, dos textos da Constituição referentes à ação direta de inconstitucionalidade e à ação direta de constitucionalidade, tinham sido estabelecido dois regimes diversos. A declaração de procedência da ação direta de inconstitucionalidade tinha eficácia erga omnes (atingia a todos), mas não tinha efeito vinculante. Isso seria dizer que, se a Administração ou o Poder Judiciário aplicasse determinado ato normativo declarado inconstitucional por ação direta de inconstitucionalidade, o prejudicado teria de buscar os meios legais e recursais para sua invalidação administrativa ou judicial. (...) Na caminhada em direção ao reconhecimento do efeito vinculante na ação direta de inconstitucionalidade, um grande passo certamente foi dado com a Lei 9.868, de 10.11.1999, que regulamentou o processo e julgamento das ações diretas de inconstitucionalidade e de constitucionalidade. Esse diploma legal equiparou os efeitos das decisões que reconhecem a constitucionalidade ou inconstitucionalidade de ato normativo em ambas as ações (...). Foi o reconhecimento legal do efeito vinculante na ção direta de inconstitucionalidade, apesar do silêncio costitucional. (...) Por fim, vem a Emenda Constitucional 45/04 dando nova redação ao $\S 2^{\circ}$ do art. 102 da Constituição Federal. Ao consagrar o entendimento predominante no Supremo Tribunal Federal, ela afasta quaisquer dúvidas quanto à presença do efeito vinculante na ação direta de inconstitucionalidade." (SOUZA, Marcelo Alves Dias de. Do precedente à sumula vinculante. Curitiba: Juruá, $1^{\mathrm{a}}$ edição (ano 2006), 2a reimpressão (ano 2013), p. 211-217).

12 "É sabido que não são idênticos os sistemas jurídicos dos dois países. Não damos aos precedentes judiciais a mesma força que têm nas nações de origem britânica. E seus juristas, afeiçoados a uma prstigiosa tradição de direito pretoriano, teriam de ser mais hostis do que nós às codificações, princípio de organização do direito a que sempre fomos habituados." (LEAL, Victor Nunes. "A súmula do Supremo Tribunal Federal e o restatement of the law dos norte-americanos". Legislação do Trabalho, ano 30, jan-fev, 1966).

13 "Neste ponto da nosssa análise comparativa é que está a superioridade prática, para nós, da Súmula do Supremo Tribunal Federal, porque, não sendo ela um Código, também não é um simples repositório particular de jurisprudência. É uma consolidação jurisprudencial autorizada com efeitos processuais, porque a inscrição de enunciados na Súmula, com a sua supressão, depende de formal deliberação do Supremo Tribunal. E a autoridade do Supremo Tribunal para assim proceder deriva dos seus poderes regimentais, tanto expressos como imanentes, e da prerrogativa, que lhe confere a Constituição de uniformizar o entendimento do direito federal." (LEAL, Victor Nunes. “Atualidades do Supremo Tribunal Federal”. Revista Forense, vol. 208, out-dez, 1964).

${ }^{14}$ BAHIA, Alexandre Gustavo Melo Franco. "As Súmulas Vinculantes e a Nova Escola da Exegese”. Revista de Processo. São Paulo: RT, vol. 206, 2012, p. 361.

${ }^{15}$ Lenio Luiz Streck e Georges Abboud afirmam que “'o precedente não cabe na súmula'. Trata-se de um 'enigma' hermenêutico que deve ser decifrado. É impossível transformar o problema da aplicação (Anwendungsdiskurs) em um problema de validade (prévia) dos discursos jurídicos (discursos de justificação Begründungsdiskurs). O problema é que isso já acontece de há muito no direito de terrae brasilis. Aliás, é prática recorrente - afinal, não há sentença ou acórdão que assim não proceda - a mera menção de ementas de acórdãos, utilizados como pautas gerais nas decisões. Tal circunstância acarreta um enfraquecimento da força persuasiva da doutrina, deixando-se a tarefa de atribuição do sentido das leis aos tribunais, fenômeno que é retroalimentado por uma verdadeira indústria de manuais jurídicos, que colacionam ementários para servirem de "pautas gerais". Verbetes. Enunciados. Tentativas de conceptualizações. Nada mais, nada menos do que a velha metafísica, recheada de conceitos sem coisas. Por tudo isso, as súmulas (vinculantes ou não) não deveriam causar surpresa. E nem estranheza. Elas sempre estiveram aí, no nosso imaginário.” (STRECK, Lenio Luiz; ABBOUD, Georges. 0 que é isto - o precedente judicial e as súmulas vinculantes?. Porto Alegre: Livraria do Advogado Editora, 2013, p. 78)

${ }^{16}$ Note-se que o Congresso Nacional e o próprio Supremo Tribunal Federal não estão vinculados aos enunciados das súmulas, de modo a garantir o princípio da reserva legal, possibilitando que o Congresso Nacional edite ato normativo que revogue indiretamente o teor da súmula vinculante; bem como, possibilitar que a Corte Suprema altere seu entendimento. 
Note-se que o legislador infraconstitucional, visando a dar efetividade aos enunciados de súmulas e a reduzir o número de recursos nos Tribunais, estabeleceu o procedimento de inadmissão de recurso, que impugna decisum que está em conformidade com súmula do Superior Tribunal de Justiça ou do Supremo Tribunal Federal, conforme dispõem os artigos 518, $\S 1^{\circ}$ (redação dada pela Lei no 11.276/2006), e 557 (redação dada pela Lei no 9.756/1998) do Código de Processo Civil de 1973.

O instituto da repercussão geral no recurso extraordinário, instituído na Emenda Constitucional $n^{\circ} 45 / 2004$ e regulamentado pela Lei $n^{\circ} 11.418 / 2006$, estabeleceu a padronização das decisões do Supremo Tribunal Federal, proferidas em controle incidental de constitucionalidade, ao dispor, no $\$ 3^{\circ}$ do artigo 543-B do Código de Processo Civil de 1973, que, "julgado o mérito do recurso extraordinário, os recursos sobrestados serão apreciados pelos Tribunais, Turmas de Uniformização ou Turmas Recursais, que poderão declará-los prejudicados ou retratar-se". Portanto, atualmente, nos recursos extraordinários, apesar do controle de constitucionalidade ser difuso, a análise da constitucionalidade é feita em tese (de forma abstrata), de modo a orientar os demais Tribunais a adotar o mesmo entendimento ${ }^{18}$.

Note-se, inclusive, que parte da doutrina vem entendendo que houve a mutação constitucional acerca dos efeitos das decisões proferidas em controle difuso de constitucionalidade, de modo que estas decisões são dotadas de efeitos obrigatórios e gerais, conforme ocorre com as decisões firmadas em controle concentrado de constitucionalidade $^{192021}$. Os adeptos deste entendimento, consequentemente, sugerem que é necessária nova interpretação do artigo 52, inciso X, da Constituição da República de 1988, que atribui ao Senado Federal o poder de suspender a execução de lei declarada inconstitucional por decisão definitiva do Supremo Tribunal Federal, de modo que o papel do Senado Federal se restringiria ao simples efeito de dar publicidade ao entendimento ${ }^{22}$.

\footnotetext{
${ }^{17}$ Misabel de Abreu Machado Derzi e Thomas da Rosa de Bustamante destacam que "a própria existência de súmulas pode constituir um risco para a independência das instâncias ordinárias do Poder Judiciário. Com efeito, muitas vezes se adota um desenho institucional que exarceba o âmbito da aplicação do princípio da praticidade, estendendo-o não apenas à esfera da Administração e da Legislação, mas tambpém da Administração da Justiça. Surge o risco de uma massificação das decisões judiais, uma desatenção às particularidades do caso, que constituem uma ameaça à dimensão da justiça do caso concreto. Uma aplicação mecanizada e automática das súmulas pode gerar uma deslegitimação do Judiciário na medida em que ele perde a capacidade de ajustar o direito aos casos concretos e, dessa forma, realizar a justiça em toda a sua plenitude." (DERZI, Misabel de Abreu Machado; BUSTAMANTE, Thomas da Rosa de. "A súmula vinculante no direito penal tributário: uma nota crítica à decisão do Supremo Tribunal Federal no julgamento do HC 108.093/ES. Revista Dialética de Direito Tributário. vol. 200, maio-2012, p. 78-94, esp. 93).
} 
18 Eis a manifestação do Ministro Gilmar Ferreira Mendes no Processo Administrativo no 318.715/STF: “O recurso extraordinário deixa de ter caráter marcadamente subjetivo ou de defesa de interesse das partes, para assumir, de forma decisiva, a função de defesa da ordem constitucional objetiva. Trata-se de orientação que os modernos sistemas de Corte Constitucional vêm conferindo ao recurso de amparo e ao recurso constitucional (...). A função do Supremo nos recursos extraordinários - ao menos demodo imediato - não é a de resolver litígios de fulano ou beltrano, nem a de revisar todos os pronunciamentos das Cortesinferiores. O processo entre as partes, trazido à Corte, via recurso extraordinário, deve ser visto apensa como pressuposto para uma atividade jurisdicional que transcende os interesses subjetivos." (Apud MADOZ, Wagner Amorim. "O recurso extraordinário interposto de decisão de Juizados Especiais Federais”. Revista de Processo. São Paulo: RT, vol. 119, 2005, p. 75-76).

${ }^{19}$ Gilmar Ferreira Mendes argumenta que "a natureza idêntica do controle de constitucionalidade, quanto às suas finalidades e aos procedimentos comuns dominantes para os modelos difuso e concentrado, não mais parece legitimar a distinção quanto aos efeitos das decisões proferidas no controle direto e no controle incidental. Somente essa nova compreensão parece apta a explicar o fato de o Tribunal ter passado a reconhecer efeitos gerais à decisão proferida em sede de controle incidental, independentemente da intervenção do Senado. O mesmo há de se dizer das várias decisões legislativas que reconhecem efeito transcendente às decisões do STF tomadas em sede de controle difuso. Esse conjunto de decisões judiciais e legislativas revela, em verdade, uma nova compreensão do texto constitucional no âmbito da Constituição de 1988. É possível, sem qualquer exagero, falar-se aqui de uma autêntica mutação constitucional em razão da completa reformulação do sistema jurídico e, por conseguinte, da nova compreensão que se conferiu à regra do art. 52, X, da Constituição de 1988. Valendonos dos subsídios da doutrina constitucional a propósito da mutação constitucional, poder-se-ia cogitar aqui de uma autêntica reforma da Constituição sem expressa modificação do texto." (MENDES, Gilmar Ferreira. "O papel do Senado Federal no controle de constitucionalidade: um caso clássico de mutação constitucional". Revista de informação legislativa, v. 41, n. 162, p. 164-165, abr./jun. de 2004).

${ }^{20}$ Luís Roberto Barroso entende que, "com a criação da ação genérica de inconstitucionalidade, pela EC 16/65, e com o contorno dado à ação direta pela Constituição de 1988, essa competência atribuída ao Senado tor nou-se um anacronismo. Uma decisão do Pleno do Supremo Tribunal Federal, seja em controle incidental ou em ação direta, deve ter o mesmo alcance e produzir os mesmos efeitos. Respeitada a razão histórica da previsão constitucional quando de sua instituição em 1934, já não há mais lógica razoável em sua manutenção. Também não parece razoável e lógica, com a vênia devida aos ilustres autores que professam entendimento diverso, a negativa de efeitos retroativos à decisão plenária do Supremo Tribunal Federal que reconheça a inconstitucionalidade de uma lei. Seria uma demasia, uma violação ao princípio da economia processual, obrigar um dos legitimados do art. 103 a propor ação direta para produzir uma decisão que já se sabe qual é!" (BARROSO, Luís Roberto. Controle de constitucionalidade no direito brasileiro: exposição sistemática da doutrina e análise crítica da jurisprudência. 2 ed. São Paulo: Saraiva, 2006, p. 111).

21 Em sentido contrário, Nelson Nery Júnior defende que "a superação da CF 52 X não é manifestação de mutação constitucional por duas razões básicas. Primeiro, porque a mutação constitucional é processo de interpretação natural da $\mathrm{CF}$, de modo que não pode ser construída de maneira forçada. Há de ser processo de mudança de paradigma constitucional (Legitimation durch Verfahren), e não o fundamento que se pretende utilizar para modificar a Constituição. Segundo, porque o limite da mutação constitucional é o próprio texto da Constituição. Não se pode fazer tábua rasa do texto da CF 52 X, que ainda se encontra em vigor e só pode ser desconsiderado por expressa mudança formal e material da Constituição, por intermédio do processo de emenda constitucional (CF 60). O objeto do processo de controle abstrato, concentrado de constitucionalidade é a declaração, mesma, de inconstitucionalidade. Por isso é que a decisão do STF em ADIn faz coisa julgada material erga omnes, independentemente da co-participação do Senado nesse procedimento, decisão essa proferida principaliter. O objeto do processo de controle concreto, difuso de constitucionalidade não é a declaração da inconstitucionalidade, que será decidida pelo STF apenas incidenter tantum e, por isso, não faz coisa julgada material nem para as partes do processo. Esses dois regimes, absolutamente distintos, hão de ser preservados como estão, sob pena de violar-se o devido processo legal (CF 5 ${ }^{\circ}$ caput e LIV)" (NERY JÚNIOR, Nelson. "O Senado Federal e o controle concreto de constitucionalidade de leis e de atos normativos: separação de poderes, Poder Legislativo e interpretação da CF 52 X". Revista de informação legislativa. v.47, n ${ }^{\circ}$ 187, p. 193-200, jul./set. de 2010). Também com entendimento contrário à tese da mutação constitucional: PEDRON, Flávio Quinaud. Mutação constitucional na crise do positivismo jurídico: história e crítica do conceito no marco da teoria do direito como integridade. Belo Horizonte: Arraes Editores, 2012. 
Outro exemplo de reforma processual, que instituiu mecanismo para a padronização decisória, através da observância da jurisprudência dos Tribunais Superiores ${ }^{23}$, é a Lei n ${ }^{\circ}$ 11.672/2008, que introduziu o artigo 543-C do Código de Processo Civil de 1973, dispondo sobre o procedimento de julgamento dos recursos especiais "repetitivos", aqueles em que se discute a mesma questão de direito ${ }^{24}$. Neste caso, constatada a "multiplicidade de recursos com fundamento em idêntica questão de direito", será selecionado o recurso especial representativo da controvérsia, ficando sobrestados os demais recursos especiais. Após o julgamento do recurso especial representativo da controvérsia, os recursos especiais que ficaram sobrestados na origem: (i) terão seguimento denegado na hipótese de o acórdão recorrido coincidir com a orientação do Superior Tribunal de Justiça; ou (ii) serão novamente examinados pelo tribunal de origem na hipótese de o acórdão recorrido divergir da orientação do Superior Tribunal de Justiça.

\footnotetext{
22 "Assim, parece legítimo entender que, hodiernamente, a fórmula relativa à suspensão de execução da lei pelo Senado Federal há de ter simples efeito de publicidade. Desta forma, se o Supremo Tribunal Federal, em sede de controle incidental, chegar à conclusão, de modo definitivo, de que a lei é inconstitucional, esta decisão terá efeitos gerais, fazendo-se a comunicação ao Senado Federal para que este publique a decisão no Diário do Congresso. Tal como assente, não é (mais) a decisão do Senado que confere eficácia geral ao julgamento do Supremo. A própria decisão da Corte contém essa força normativa. Parece evidente ser essa a orientação implícita nas diversas decisões judiciais e legislativas acima referidas. Assim, o Senado não terá a faculdade de publicar ou não a decisão, uma vez que se não cuida de uma decisão substantiva, mas de simples dever de publicação, tal como reconhecido a outros órgãos políticos em alguns sistemas constitucionais (Constituição austríaca, art. 140,5 - publicação a cargo do Chanceler Federal, e Lei Orgânica da Corte Constitucional Alemã, art. 31, (2) publicação a cargo do Ministro da Justiça). A não-publicação não terá o condão de impedir que a decisão do Supremo assuma a sua real eficácia. Essa solução resolve de forma superior uma das tormentosas questões da nossa jurisdição constitucional. Superam-se, assim, também, as incongruências cada vez mais marcantes entre a jurisprudência do Supremo Tribunal Federal e a orientação dominante na legislação processual, de um lado, e, de outro, a visão doutrinária ortodoxa e - permita-nos dizer - ultrapassada do disposto no art. 52, X, da Constituição de 1988." (MENDES, Gilmar Ferreira. "O papel do Senado Federal no controle de constitucionalidade: um caso clássico de mutação constitucional”. Revista de informação legislativa. v. 41, n.
} 162, p. 165-166, abr./jun. de 2004).

${ }^{23}$ GONÇALVES, Gláucio Ferreira Maciel; SILVA, Maria Isabel Amarato Felippe da. "Recurso especial repetitivo: a obrigatoriedade da observância da jurisprudência do Superior Tribunal de Justiça pelos tribunais de origem". Revista da Faculdade de Direito da Universidade Federal de Minas Gerais. vol. 60, 2012, p. 121-145.

\footnotetext{
${ }^{24}$ Eis a lição de Humberto Theodoro Júnior acerca da constitucionalidade do artigo 543-C do Código de Processo Civil: "Como o recurso especial não é um instrumento de revisão dos julgamentos dos tribunais locais em toda a extensão da lide, mas apenas a reapreciação da tese de direito federal em jogo, não se pode considerar, em princípio, ofensiva ao acesso àquele recurso constitucional a restrinção imposta ao seu julgamento diante de cusas seriadas ou repetitivas." (THEODORO JÚNIOR, Humberto. "Recurso especial e o novo artigo 543-C do Código de Processo Civil (Lei no 11.672, de 08.05.08)". Revista Magister de Direito Civil e Processual Civil. São Paulo: Magister, n 24, jun.-2008, p. 31-32).
} 
Nesta tendência de reformas legislativas, em outubro de 2009, o então Presidente do Senado Federal, Senador José Sarney, designou comissão de juristas, presidida pelo Ministro Luiz Fux, para elaborar o Anteprojeto de Lei do novo Código de Processo Civil. Após ser aprovado no Senado Federal (sob a relatoria do Senador Valter Pereira), o Projeto de Lei tramitou na Câmara dos Deputados (sob a relatoria do Deputado Federal Paulo Teixeira), retornando ao Senado Federal, onde teve sua redação final concluída, sendo sancionado pela Presidente da República em 17 de março de 2015.

A análise da Exposição de Motivos do Anteprojeto permite evidenciar que o compromisso da comissão de juristas foi com a celeridade, ao fundamento de que, "sendo ineficiente o sistema processual, todo o ordenamento jurídico passa a carecer de real efetividade. De fato, as normas de direito material se transformam em pura ilusão, sem a garantia de sua correlata realização, no mundo empírico, por meio do processo. (...) O novo Código de Processo Civil tem o potencial de gerar um processo mais célere, mais justo, porque mais rente às necessidades sociais e muito menos complexo" (BRASIL, 2009, p. 1112).

No tocante ao sistema de precedente judicial, constata-se que a Exposição de Motivos do Anteprojeto do novo Código de Processo Civil, bem como o relatório do Deputado Federal Paulo Teixeira, são claros no sentido de que um dos propósitos da reforma legislativa foi expressamente força vinculante aos precedentes judiciais ${ }^{25} 26$.

\footnotetext{
25 Exposição de Motivos do Anteprojeto do Novo Código de Processo: "Está-se, aqui, diante de poderoso instrumento, agora tornado ainda mais eficiente, cuja finalidade é a de uniformizar a jurisprudência dos Tribunais superiores, interna corporis. Sem que a jurisprudência desses Tribunais esteja internamente uniformizada, é posto abaixo o edifício cuja base é o respeito aos precedentes dos Tribunais superiores." (BRASIL. Anteprojeto do novo Código de Processo Civil. Disponível em: [www.senado.gov.br/senado/novocpc/pdf/Anteprojeto.pdf]. Acesso em: 05.08.2015).

${ }^{26}$ Relatório do Deputado Federal Paulo Teixeira: "O relatório manteve o sistema, acolhido no projeto aprovado pelo Senado Federal, de atribuir eficácia vinculante aos precedentes judiciais. Busca-se aperfeiçoá-lo, porém. Em primeiro lugar, modifica-se topologicamente o trato do tema, levando-o para o capítulo que trata da sentença e da coisa julgada, de modo a deixar claro que se trata de atribuir eficácia vinculante aos provimentos judiciais finais. Aperfeiçoa-se a terminologia do projeto, de modo a deixar clara a eficácia vinculante dos precedentes judiciais, regulamentando-se, também, a eficácia das decisões que superam os precedentes vinculantes, de forma a respeitar os princípios da segurança jurídica, confiança e isonomia. Busca-se, ainda, regular os casos em que a eficácia vinculante não incide, de modo a permitir a correta distinção entre o caso que deu origem ao precedente vinculante e um caso concreto posterior que, por ser diferente daquele, não deva ser julgado da mesma maneira." (BRASIL. Câmara dos Deputados. Substitutivo aos Projetos de Lei n. 6.025, de 2005 e 8.046, de 2010 Relator: Dep. Federal Paulo Teixeira. Disponível em: [http://www.camara.gov.br/proposicoesWeb/prop_mostrarintegra;jsessionid=66088F819F19510349C336A782D 8BC3D.node1 ?codteor=1086929\&filename=Parecer-PL602505-08-05-2013]. Acesso em: 05.08.2015).
} 
Neste sentido, em clara convergência da tradição civil law com a common law, o novo Código de Processo Civil disciplina que os juízes devem se vincular ao direito jurisprudencial formado nos tribunais, ao dispor, em seu artigo 927, que os juízes observarão: (I) as decisões do Supremo Tribunal Federal em controle concentrado de constitucionalidade; (II) os enunciados de súmula vinculante; (III) os acórdãos em incidente de assunção de competência ou de resolução de demandas repetitivas e em julgamento de recursos extraordinário e especial repetitivos; (IV) os enunciados das súmulas do Supremo Tribunal Federal em matéria constitucional e do Superior Tribunal de Justiça em matéria infraconstitucional; e (V) a orientação do plenário ou do órgão especial aos quais estiverem vinculados.

Portanto, o Código de Processo Civil de 2015 prevê uma hierarquia de enunciado de súmulas e de decisões judiciais a serem seguidas obrigatoriamente pelos juízes e pelos Tribunais.

Esta tendência padronização decisória, com a atribuição de força vinculante às decisões judiciais dos Tribunais Superiores, está em conformidade com um dos mais importantes princípios do Estado Democrático de Direito: a segurança jurídica, que visa a proteger a confiança e as legítimas expectativas jurídicas. ${ }^{27}$

No entanto, necessário que tais reformas processuais, apesar de prever a aplicação vinculativa e/ou impor a observância do precedente judicial, possibilite a aplicação da técnica de distinção dos precedentes, bem como de sua superação, de modo a assegurar as garantias fundamentais do acesso à Justiça, do contraditório, da ampla defesa, do devido processo legal e da fundamentação ${ }^{28}$.

\footnotetext{
${ }^{27}$ Neil MacCormick afirma que "entre os valores que ele [o Estado de Direito] assegura, nenhum é mais importante que a certeza jurídica, exceto talvez pelos princípios que a acompanham, a saber, a segurança jurídica de expectativas jurídicas e garantia do cidadão contra interferência arbitrárias por parte do governo e de seus agentes". (MACCORMICK, Neil. Rethoric and the rule of law - A theory of legal reasoning. New York: Oxford University Press, 2005, p. 18 - Tradução: Luiz Guilherme Marinoni. Apud MARINONI, Luiz Guilherme. Precedentes Obrigatórios. São Paulo: Revista dos Tribunais, 2011, p. 120).

${ }^{28}$ Aroldo Plínio Gonçalves afirma que "as propostas de novas categorias e de novas vias que abreviem o momento da decisão são particularmente voltadas para a economia e a celeridade como predicados essenciais da decisão justa, sobretudo quando a natureza dos interesses em jogo exige que os ritos sejam simplificados. Contudo, a economia e a celeridade do processo não são incompatíveis com as garantias das partes, e a garantia constitucional do contraditório não permite que seja ele violado em nome do rápido andamento do processo. A decisão não se qualifica como justa apenas pelo critério da rapidez, e se a justiça não se apresentar no processo não poderá se apresentar, também, na sentença" (GONÇALVES, Aroldo Plínio. Técnica Processual e teoria do processo. Rio de Janeiro: Aide Ed., 1992, p. 124-125).
} 


\section{O PRINCÍPIO DA SEGURANÇA JURÍDICA E OS PRECEDENTES JUDICIAIS}

A complexidade das relações sociais, diante dos riscos decorrentes da vida em comunidade, exige a consolidação da confiança mútua entre os cidadãos para a manutenção e desenvolvimento da sociedade, o que acarreta na formação de legítimas expectativas nas ações e condutas a serem adotadas pelos sujeitos de direito.

Niklas Luhmann (1996, p. 14) afirma que:

a questão da complexidade define o problema fundamental, a partir do qual a confiança pode ser analisada funcionalmente e comparada com outros mecanismos sociais, funcionalmente equivalentes. Onde há confiança, há aumento de possibilidades para a experiência e a ação; há possibilidade do aumento da complexidade do sistema social; e também há um aumento do número de possibilidades que podem reconciliar-se com sua estrutura, porque a confiança constrói uma forma mais efetiva de redução da complexidade.

Constata-se, portanto, que a segurança jurídica é indispensável para a consolidação do Estado Democrático de Direito, na medida em que representa a confiança na estabilidade e na continuidade da ordem jurídica, de modo a assegurar ao jurisdicionado a previsibilidade das consequências jurídicas de determinada conduta ${ }^{29}$.

A Constituição da República de 1988 prevê, no caput do artigo 5ª a segurança como um dos direitos inviolados, juntamente com os direitos à vida, liberdade, igualdade e propriedade. A segurança jurídica constitui direito fundamental, que também encontra-se associado ao princípio da legalidade (inciso II, art. 5º da CR/1988), da inviolabilidade do direito adquirido, da coisa julgada e do ato jurídico perfeito (inciso XXXVI, art. $5^{\circ}$, da CR/1988), e, no âmbito penal, ao princípio da legalidade e anterioridade da lei penal (inciso XXXIX, art. $5^{\circ}$, da CR/1988) e da irretroatividade da lei penal desfavorável (inciso XL, art. $5^{\circ}$, da CR/1988) ${ }^{30}$.

Em atenção à esta garantia constitucional da segurança jurídica, o Código de Processo Civil de 2015 dispõe, em seu artigo 926, que "os tribunais devem uniformizar sua jurisprudência e mantê-la estável, íntegra e coerente".

\footnotetext{
${ }^{29}$ MARINONI, Luiz Guilherme. "O Precedente na Dimensão da Segurança Jurídica". A Força dos Precedentes. Coord: MARINONI, Luiz Guilherme. Salvador: Editora JusPodivm, 2010, p. 211.

${ }^{30}$ MARINONI, Luiz Guilherme. Precedentes Obrigatórios. $2^{\mathrm{a} e d}$., São Paulo: Revista dos Tribunais, 2011, p. 121-121.
} 
Neste sentido, o cidadão, como destinatário das normas jurídicas produzidas pelos atos legislativos, jurisdicionais e executivos, tem o direito de ter conhecimento prévio acerca do ordenamento jurídico a que esta sujeito, bem como ter a expectativa de que as consequências jurídicas previstas para determinada conduta sejam mantidas.

Cândido Ragel Dinamarco (2001, p. 1104) destaca que

toda ordem jurídica tem a missão e a responsabilidade de definir situações e gerar clima de confiança nas pessoas e grupos quanto aos seus direitos, deveres e obrigações, seja para exercê-los e cumpri-los adequadamente, seja para poderem prever consequências do descumprimento próprio ou alheio. Tal é o valor da segurança, indispensável ao convívio social harmonioso e civilizado.

Assim, verifica-se a necessidade de os órgãos jurisdicionais uniformizarem a interpretação acerca de determinada questão de direito, após o devido processo legal de discussão das teses jurídicas, com amplo contraditório entre as partes. Michele Taruffo (2011, p. 142) ressalta que "quando se fala da jurisprudência se faz normalmente referência a uma pluralidade, frequentemente bastante ampla, de decisões relativas a vários e diversos casos concretos". Portanto, é adequado que o entendimento do Tribunal se forme a partir de históricas e reiteradas decisões, de modo a permitir a evolução da jurisprudência, com o amplo debate das questões de direito ${ }^{31}$.

Note-se que a falta de uniformização da interpretação judicial implica, inclusive, no descrédito do Poder Judiciário, na medida em que os jurisdicionados não têm confiança na manutenção das decisões judiciais (aspecto externo) e os juízes de instância inferior não respeitam o entendimento de órgão mais qualificado (aspecto interno) ${ }^{32}$, o que compromete na consolidação do Estado Democrático de Direito.

\section{OS PRECEDENTES JUDICIAIS E A TEORIA DO STARE DECISIS}

O civil law e o common law são tradições jurídicas derivadas de circunstâncias políticas e culturais distintas, o que acarretou a formação de institutos e conceitos próprios em cada sistema $^{33}$. O civil law, no século XVIII, se desenvolveu a partir dos ideais da Revolução Francesa, visando a contenção do abuso de poder e idealizando a igualdade entre os homens, a ser obtida através da lei, que seria aplicável indistintamente a todas as pessoas e que preveria todas as relações jurídicas ${ }^{34}$. Por outro lado, o common law busca a equidade entre os 
cidadãos a partir da aplicação das decisões dos casos concretos já julgados aos casos semelhantes ${ }^{35}$.

Hans Kelsen (1996, 278) afirma que, no common law, "o tribunal que cria o precedente funciona como legislador, talqualmente o órgão a que a Constituição confere poder para legislar".

\begin{abstract}
${ }^{31}$ Neste sentido, eis as precisas lições de Dierle Nunes (2008, p. 38) acerca das premissas essenciais para a criação e aplicação dos precedentes judiciais: "Nesse aspecto, o processualismo constitucional democrático por nós defendido tenta discutir a aplicação de uma igualdade efetiva e valoriza, de modo policêntrico e comparticipativo, uma renovada defesa de convergência entre o civil law e common law, ao buscar uma aplicação legítima e eficiente (efetiva) do Direito para todas as litigiosidades (sem se aplicar padrões decisórios que pauperizam a análise e a reconstrução interpretativa do direito), e defendendo o delineamento de uma teoria dos precedentes para o Brasil que suplante a utilização mecânica dos julgados isolados e súmulas em nosso país. Nesses termos, seria essencial para a aplicação de precedentes seguir algumas premissas essenciais: $1^{\circ}$ Esgotamento prévio da temática antes de sua utilização como um padrão decisório (precedente): ao se proceder à análise de aplicação dos precedentes no common law se percebe ser muito difícil a formação de um precedente (padrão decisório a ser repetido) a partir de um único julgado, salvo se em sua análise for procedido um esgotamento discursivo de todos os aspectos relevantes suscitados pelos interessados. Nestes termos, mostra-se estranha a formação de um "precedente" a partir de um julgamento superficial de um (ou poucos) recursos (especiais e/ou extraordinários) pinçados pelos Tribunais (de Justiça/regionais ou Superiores). Ou seja, precedente (padrão decisório) dificilmente se forma a partir de um único julgado. $2^{\circ}$ - Integridade da reconstrução da história institucional de aplicação da tese ou instituto pelo tribunal:ao formar o precedente o Tribunal Superior deverá levar em consideração todo o histórico de aplicação da tese, sendo inviável que o magistrado decida desconsiderando o passado de decisões acerca da temática. E mesmo que seja uma hipótese de superação do precedente (overruling) o magistrado deverá indicar a reconstrução e as razões (fundamentação idônea) para a quebra do posicionamento acerca da temática. $3^{\circ}$ - Estabilidade decisória dentro do Tribunal (stare decisis horizontal): o Tribunal é vinculado às suas próprias decisões: como o precedente deve se formar com uma discussão próxima da exaustão, o padrão passa a ser vinculante para os Ministros do Tribunal que o formou. É impensável naquelas tradições que a qualquer momento um ministro tente promover um entendimento particular (subjetivo) acerca de uma temática, salvo quando se tratar de um caso diferente (distinguishing) ou de superação (overruling). Mas nestas hipóteses sua fundamentação deve ser idônea ao convencimento da situação de aplicação. $4^{\circ}$ - Aplicação discursiva do padrão (precedente) pelos tribunais inferiores (stare decisis vertical): as decisões dos tribunais superiores são consideradas obrigatórias para os tribunais inferiores ("comparação de casos"): o precedente não pode ser aplicado de modo mecânico pelos Tribunais e juízes (como v.g. as súmulas são aplicadas entre nós). Na tradição do common law, para suscitar um precedente como fundamento, o juiz deve mostrar que o caso, inclusive, em alguns casos, no plano fático, é idêntico ao precedente do Tribunal Superior, ou seja, não há uma repetição mecânica, mas uma demonstração discursiva da identidade dos casos. $5^{\circ}$ Estabelecimento de fixação e separação das ratione decidendi dos obter dicta da decisão: a ratio decidendi (elemento vinculante) justifica e pode servir de padrão para a solução do caso futuro; já o obter dictum constituem-se pelos discursos não autoritativos que se manifestam nos pronunciamentos judiciais "de sorte que apenas as considerações que representam indispensavelmente o nexo estrito de causalidade jurídica entre o fato e a decisão integram a ratio decidendi, onde qualquer outro aspecto relevante, qualquer outra observação, qualquer outra advertência que não tem aquela relação de causalidade é obiter: um obiter dictum ou, nas palavras de Vaughan, um gratis dictum." $6^{\circ}$ - Delineamento de técnicas processuais idôneas de distinção (distinguishing) e superação (overruling) do padrão decisório: A ideia de se padronizar entendimentos não se presta tão só ao fim de promover um modo eficiente e rápido de julgar casos, para se gerar uma profusão numérica de julgamentos. Nestes termos, a cada precedente formado (padrão decisório) devem ser criados modos idôneos de se demonstrar que o caso em que se aplicaria um precedente é diferente daquele padrão, mesmo que aparentemente seja semelhante, e de proceder à superação de seu conteúdo pela inexorável mudança social - como ordinariamente corre em países de common law."
\end{abstract}

${ }^{32}$ LIMA, Tiago Asfor Rocha. Precedentes Judiciais Civis no Brasil. São Paulo: Saraiva, 2013, p. 165. 
A tradição do common law é constituída pela teoria do stare decisis ${ }^{36}$, que prevê a eficácia vinculante (vertical, porque o entendimento dos órgãos superiores vinculam os hierarquicamente inferiores; e horizontal, porque, em regra, o precedente deve ser seguido pelo Tribunal que o formou) da ratio decidendi dos precedentes judiciais.

\subsection{A RATIO DECIDENDI E O OBITER DICTUM: UMA ANÁLISE INTERPRETATIVA}

O exercício do direito jurisprudencial necessita da análise interpretativa para se apurar a razão de decidir (ratio decidendi) do precedente judicial.

Para a aplicação de determinado precedente judicial é necessário que o juiz o analise, de modo a separar a essência da tese jurídica (ratio decidendi) dos argumentos jurídicos acessórios e secundários, expostos apenas de passagem na decisão (obter dictum), pois apenas a ratio decidendi que se vincula ao julgamento dos demais processos.

O melhor lugar para se buscar a tese jurídica de um precedente está na sua fundamentação, na medida em que são as razões que embasaram o provimento jurisdicional, que levaram à fixação do dispositivo. A interpretação do precedente deve envolver a análise da decisão judicial como um todo, desde o relatório até a parte dispositiva. Contudo, o significado de um precedente está, essencialmente, na sua fundamentação, de modo que não basta olhar somente à sua parte dispositiva ${ }^{37}$.

\footnotetext{
${ }^{33}$ MARINONI, Luiz Guilherme. Precedentes Obrigatórios. 2aad., São Paulo: Revista dos Tribunais, 2011, p. 23.

34 Eduardo Cambi e Thiago Baldani Gomes de Cambi destacam que "no período anterior à Revolução Francesa (1789), não se concebia um Poder Judiciário independente, pois não havia exata delimitação da atividade jurisdicional. Os juízes, com frequência, decidiam com base na vontade dos governantes. Após a revolução, em aplicação extrema da legalidade estrita, justamente para se atender aos anseios burgueses de então, a atividade jurisdicional passou a ser adstrita apenas à aplicação das leis, dispensando-se qualquer exercício de interpretação." (CAMBI, Eduardo; FILIPPO, Thiago Baldani Gomes de. "Precedentes Vinculantes". Revista de Processo. São Paulo: RT, vol. 215, 2013, p. 215).

${ }^{35}$ CAMBI, Eduardo; FILIPPO, Thiago Baldani Gomes de. "Precedentes Vinculantes". Revista de Processo. São

Paulo: RT, vol. 215, 2013, p. 214-215.
} 
${ }^{36} \mathrm{O}$ termo vem da expressão latina "stare decisis et non quieta movere”, que significa: "mantenha-se a decisão e não moleste o que foi decidido”.

Neste sentido, Thomas da Rosa de Bustamante (2012, p. 259) ressalta que os "precedentes judiciais são, como enunciados legislativos, textos dotados de autoridade que carece de interpretação. É trabalho do aplicador extrair a ratio decidendi - o elemento vinculante - do caso a ser utilizado como paradigma".

\subsection{A TÉCNICA DE DISTINÇÃO DOS PRECEDENTES JUDICIAIS (DISTINGUISHING): OUTRA ANÁLISE INTERPRETATIVA}

O direito jurisprudencial dá grande relevo aos fatos do caso, seja quando da elaboração do precedente, em geral hard cases, seja quando da análise dos precedentes. É necessário que o juiz analise os elementos fáticos do precedente judicial, de modo a verificar se há semelhança com o caso sob julgamento.

Constatando-se que os fatos relevantes ${ }^{38}$ do precedente judicial são distintos do caso sob julgamento, o juiz pode: (i) dar à ratio decidendi uma interpretação restritiva, por entender que peculiaridades do caso concreto impedem a aplicação da mesma tese jurídica outrora firmada (restrictive distinguishing), caso em que julgará o processo livremente, sem vinculação ao precedente; ou (ii) estender ao caso a mesma solução conferida aos casos anteriores, por entender que, a despeito das peculiaridades concretas, aquela tese jurídica lhe é aplicável (ampliative distinguishing) ${ }^{39}$.

René David (1996, p. 352) destaca que o uso das técnicas do distinguishing deve ser utilizado com cautela, na medida em que "o uso indiscriminado do poder de distinguir pode levar a se duvidar, de modo geral, da real vinculação aos precedentes obrigatórios e, consequentemente, levar à falência do sistema, o que, com certeza, não é desejado”.

Contudo, Neil Duxbury (2011, p. 328) ressalta que os advogados e os juízes têm controle sobre eventual utilização indevida e reiterada da técnica de distinção dos precedentes:

\footnotetext{
${ }^{37}$ MARINONI, Luiz Guilherme. "Uma nova realidade diante do Projeto de CPC: a ratio decidendi ou os fundamentos determinantes da decisão”. Revista dos Tribunais. São Paulo: RT, vol. 918, 2012, p. 355.
} 
O juiz que tenta 'distinguir' casos com base em fatos materialmente irrelevantes está propenso a ser facilmente descoberto. Advogados e outros juízes que têm razões para controlar sua atividade provavelmente não terão dificuldade em evidenciar a sua atividade como de alguém descuidado ou desonesto, e, então, sua reputação será desgastada e sua decisão questionada. O fato de os juízes terem o poder de 'distinguir' não significa que eles podem negar os precedentes quando lhes for conveniente.

\section{A TÉCNICA DE SUPERAÇÃO DOS PRECEDENTES JUDICIAIS (OVERRULING)}

Thomas da Rosa de Bustamante (2012, p. 395) destaca que

O que justifica a própria autoridade da jurisprudência é a racionalização do Direito positivo, sua sintonia com as ideias de correção, justiça, imparcialidade. Portanto, ainda que se reconheça a existência de razões de autoridade que militam a favor da vinculação ao precedente judicial - visualizando o precedente como uma fonte normativa que encontra sustentação tanto nessas razões de autoridade quanto em argumentos puramente racionais, sendo que em caso de conflito entre esses dois tipos de justificação é necessária uma ponderação entre eles - essas razões não podem ter força absoluta: o poder de estabelecer o case law deve englobar também o de revisá-lo, aperfeiçoá-lo, viabilizar sua evolução, ainda que sob certos limites.

Assim, apesar de os fatos relevantes do precedente judicial serem semelhantes ao caso sob judice, é possível que o juiz queira decidir de outra maneira, por entender que a valoração dessas circunstâncias mudou ${ }^{40}$.

A força vinculante do precedente não impede que uma determinada tese dominante, antes sedimentada, possa ser superada, passando-se a um novo processo de "normatização pretoriana". A mutação progressiva de paradigmas de um determinado episódio da vida, dotado de relevância jurídica, sempre veio imposta pela historicidade da realidade social, constituindo mesmo uma exigência de justiça ${ }^{41}$.

Contudo, a decisão que promover a superação do precedente judicial (overruling) exige como pressuposto uma fundamentação precisa, suscitando argumentos ainda não analisados, bem como apresentando uma justificação complementar acerca da necessidade de superação do precedente (dever de levar em consideração o precedente, com fundamento no princípio da universalidade e da imparcialidade na atividade judiciária).

J. W. Harris, na obra Towards principles of overruling - When should a final court of appeal second guess?, apresentou os princípios jurídicos que devem orientar a utilização (ou 
não) do overruling. O princípio da "ausência de novas razões" ou do "caráter definitivo" das decisões da House of Lords é aplicável às decisões intrinsecamente incorreta (quando as razões consideradas não foram corretamente ponderadas $)^{42}$.

Para J. W. Harris, a finalidade da Corte é unificar o Direito, não justificando alterar o entendimento se não foram alegadas novas razões relevantes, de modo a assegurar a definitividade das questões jurídicas. O princípio da confiança justificada visa a garantir a proteção da confiança do jurisdicionado e das expectativas criadas, não sendo adequado a utilização de um distinguish forçado (com base em fundamento inadequados), ao invés da prática do overruling. O princípio do "respeito ao legislador" consiste na preocupação que a Corte deve ter de não revogar seus próprios precedentes quando o Poder Legislativo já aderiu ao entendimento, atuando sob a pressuposição de que a regra anterior faz parte do Direito positivo. Por fim, J. W. Harris aponta a regra de vinculação ao caso concreto, que dispõe que a Corte somente deve revisar o Direito onde há uma disputa concreta, vedando a prática do overruling à debates meramente acadêmicos ${ }^{43}$.

Portanto, constata-se que o overruling é uma técnica excepcional, que se compatibiliza com a força vinculante em sentido forte do precedente judicial; tanto que, para superar o case law, é necessário um discurso de justificação normativa.

\footnotetext{
${ }^{38}$ Arthur L. Goodhart, ao expor seu método para a apuração da ratio decidendi, explica que é necessário separar os fatos que o juiz admitiu como materiais para decidir: "Tendo determinado, como primeiro passo, todos os fatos do caso tais como vistos pelo juiz, é então necessário descobrir em quais destes fatos ele encontrou material para o seu julgamento" - tradução: Luiz Guilherme Marinoni. (No original: "Having, as a first step, determined all the facts of the case as seen by the judge, it is then necessary to discover which of these facts he has found material for his judgment") (Arthur L. Goodhart, "Determining the ratio decidendi of a case". Essays in Jurisprudence and the Common Law. Cambridge, University Press, 1931, p. 15. Apud MARINONI, Luiz Guilherme. "Uma nova realidade diante do Projeto de CPC: a ratio decidendi ou os fundamentos determinantes da decisão". Revista dos Tribunais. São Paulo: RT, vol. 918, 2012, p. 359).
}

39 DIDIER JR., Fredie; BRAGA, Paula Sarno; OLIVEIRA, Rafael Alexandria de. Curso de Direito Processual

Civil. Salvador: Editora Juspodivm, vol. II, 2013, p. 454.

${ }^{40}$ ALEXY, Robert. Teoria da argumentação juridica. A teoria do discurso racional como técnica da fundamentação jurídica. Trad. Zilda Hutchinson Schild Silva. Revisão técnica da tradução e introdução à edição brasileira: Cláudia Toledo. 2ª ed. São Paulo: Landy, 2005, p. 265.

${ }^{41}$ TUCCI, José Rogério Cruz e. Precedente judicial como fonte do direito. São Paulo: RT, 2004, p. 180.

${ }^{42}$ Segundo J. W. Harris, não se inclui nesse princípio as decisões incorretas por razões estruturais, nas quais não foram debatidas eventuais razões relevantes capazes de alterar o precedente.

43 cf. BUStamante, Thomas da Rosa de. Teoria do Precedente Judicial. A justificação e a aplicação das regras jurisprudenciais. São Paulo: Noeses, 2012, p.396-401. 


\section{CONSIDERAÇÕES FINAIS}

Mauro Cappelletti e Bryant Garth (1988, p. 12) ensinam que o acesso à Justiça deve "ser encarado como o requisito fundamental - o mais básico dos direitos humanos - de um sistema jurídico moderno e igualitário que pretenda garantir, e não apenas proclamar os direitos de todos" ${ }^{44}$. Neste sistema, os juristas precisam reconhecer que "as técnicas processuais servem a funções sociais" ${ }^{45}$, de modo que a questão do acesso à Justiça tem que ser o ponto central da moderna processualística. O grande e crescente número de indivíduos, grupos e interesses, antes não representados, que agora têm acesso aos tribunais e a mecanismos semelhantes acarreta em pressão sobre o sistema judiciário, no sentido de reduzir a sua carga e encontrar procedimentos ainda mais baratos. ${ }^{46}$ Contudo, os referidos juristas ressaltam que "não se pode permitir que essa pressão, que já é sentida, venha a subverter os fundamentos de um procedimento justo" (1988, p. 164).

No Brasil, institui-se, recentemente, com as ultimas reformas na legislação processual, principalmente, tendência de padronização decisória, em clara convergência das tradições civil law e common law. O Código de Processo Civil de 2015, suscitando os princípios da legalidade, da segurança jurídica, da duração razoável do processo, da proteção da confiança e da isonomia, atribui expressa força vinculante às decisões judiciais dos Tribunais Superiores formadas na sistemática dos recursos repetitivos, revelando a tendência de valorização crescente do uso de julgados como se fossem os precedentes do common law e da necessidade de criação de técnicas de julgamento vocacionadas à padronização decisória.

Neste sentido, torna-se necessário que o sistema processual brasileiro, apesar de prever a aplicação vinculativa e/ou impor a observância do precedente judicial, possibilite a aplicação da técnica de distinção dos precedentes, bem como de sua superação, de modo a assegurar as garantias fundamentais do acesso à Justiça, do contraditório, da ampla defesa, do devido processo legal e da fundamentação.

\footnotetext{
${ }^{44}$ CAPPELlETTI, Mauro; GARTH, Bryant. Acesso à Justiça. Tradução: Ellen Graice Northfleet. Porto Alegre: Fabris, 1988, p. 12.

${ }^{45}$ Idem.

${ }^{46}$ Ibidem, p. 164.
} 
Em atenção ao princípio da segurança jurídica, deve-se também possibilitar a atribuição dos efeitos prospectivos, no caso da superação de um entendimento consolidado, diante da confiança justificada que existia em relação ao precedente.

\section{REFERÊNCIAS BIBLIOGRÁFICAS E CITAÇÕES}

ALEXY, Robert. Teoria da argumentação juridica. A teoria do discurso racional como técnica da fundamentação jurídica. Trad. Zilda Hutchinson Schild Silva. Revisão técnica da tradução e introdução à edição brasileira: Cláudia Toledo. $2^{\mathrm{a}}$ ed. São Paulo: Landy, 2005. BAHIA, Alexandre Gustavo Melo Franco. “As Súmulas Vinculantes e a Nova Escola da Exegese”. Revista de Processo. São Paulo: RT, vol. 206, 2012.

BARROSO, Luis Roberto. "Constituição, Democracia e Supremacia Judicial: Direito e política no Brasil contemporâneo". As Novas Faces do Ativismo Judicial. Coord: FELLET, André Luiz Fernandes; PAULA, Daniel Giotti de; NOVELINO, Marcelo. Salvador: Editora JusPodivm. 2013.

. "Elementos para a construção de um Direito Jurisprudencial". In MELLO, Patrícia Perrone Campos. Precedentes: O desenvolvimento judicial do direito no constitucionalismo contemporâneo. Rio de Janeiro: Renovar, 2008.

Controle de constitucionalidade no direito brasileiro: exposição sistemática da doutrina e análise crítica da jurisprudência. 2 ed. São Paulo: Saraiva, 2006.

BRASIL. Anteprojeto do novo Código de Processo Civil. 2010. Disponível em: [www.senado.gov.br/senado/novocpc/pdf/Anteprojeto.pdf].

. Câmara dos Deputados. da Câmara dos Deputados ao Projeto de Lei $n^{0}$ 8.046-A de 2010 do Senado Federal - Relator: Dep. Federal Paulo Teixeira. Disponível em:

[http://www.camara.gov.br/proposicoesWeb/prop_mostrarintegra;jsessionid=83FA88A685E CA17610F749488C439825.proposicoesWeb2?codteor=1246935\&filename=TramitacaoPL+8046/2010]. 
.. Câmara dos Deputados. Substitutivo aos Projetos de Lei n. 6.025, de 2005 e 8.046, de 2010 - Relator: Dep. Federal Paulo Teixeira. Disponível em: [http://www.camara.gov.br/proposicoesWeb/prop_mostrarintegra;jsessionid=66088F819F19 510

- Conselho Nacional de Justiça - CNJ. Estudo Comparado Sobre Recursos, Litigiosidade e Produtividade: a prestação jurisdicional no contexto internacional. Brasilia: CNJ, 2011.

BUStamante, Thomas da Rosa de. Teoria do Precedente Judicial. A justificação e a aplicação das regras jurisprudenciais. São Paulo: Noeses, 2012.

CAMBI, Eduardo; FILIPPO, Thiago Baldani Gomes de. "Precedentes Vinculantes". Revista de Processo. São Paulo: RT, vol. 215, 2013.

DAVID, René. Os grandes sistemas do direito contemporâneo. Tradução Hermínio A. Carvalho. 3. ed. São Paulo: Martins Fontes, 1996.

DERZI, Misabel de Abreu Machado; BUSTAMANTE, Thomas da Rosa de. "A súmula vinculante no direito penal tributário: uma nota crítica à decisão do Supremo Tribunal Federal no julgamento do HC 108.093/ES. Revista Dialética de Direito Tributário. vol. 200, maio-2012.

DIDIER JR., Fredie; BRAGA, Paula Sarno; OLIVEIRA, Rafael Alexandria de. Curso de Direito Processual Civil. Salvador: Editora Juspodivm, vol. II, 2013.

DINAMARCO, Cândido Ragel. Fundamentos do processo civil moderno. 4 ed. São Paulo: Malheiros, vol. 2, 2001.

DUXBURY, Neil. The nature and authority of precedent. New York: Cambridge, University Press, 2008, p. 114. Apud: MARINONI, Luiz Guilherme. Precedentes Obrigatórios. $2^{\mathrm{a}}$ ed. - São Paulo: Editora Revista dos Tribunais, 2011.

GONÇALVES, Aroldo Plínio. Técnica Processual e teoria do processo. Rio de Janeiro: Aide Ed., 1992. 
GONÇALVES, Gláucio Ferreira Maciel; SILVA, Maria Isabel Amarato Felippe da. "Recurso especial repetitivo: a obrigatoriedade da observância da jurisprudência do Superior Tribunal de Justiça pelos tribunais de origem”. Revista da Faculdade de Direito da Universidade Federal de Minas Gerais. vol. 60, 2012.

GOODHART, Arthur L.. "Determining the ratio decidendi of a case". Essays in Jurisprudence and the Common Law. Cambridge, University Press, 1931.

JAYME, Fernando Gonzaga. "Necessitamos de um Novo Código de Processo Civil?”. In: MACHADO, Felipe; CATTONI DE OLIVEIRA, Marcelo Andrade (Coord.). Constituição e Processo: uma análise hermenêutica da (re)construção dos códigos. Belo Horizonte: Fórum, 2012.

JAYME, Fernando Gonzaga; FERNANDES, Tereza de Assis. "Julgamento Liminar do Pedido - análise dos critérios de aplicação e inevitável crítica em relação a sua disciplina no Projeto de Novo Cógigo Civil". Coord: FREIRE, Alexandre, et al. Novas Tendências do processo Civil: Estudo sobre o Projeto de Novo Código de Processo Civil. Salvador: Editora JusPodivm, 2013.

KELSEN, Hans. O problema da justiça. Trad. João Batista Machado. $2^{a}$ ed., São Paulo: Martins Fontes, 1996.

LEAL, Victor Nunes. "A súmula do Supremo Tribunal Federal e o restatement of the law dos norte-americanos". Legislação do Trabalho. ano 30, jan-fev, 1966.

. "Atualidades do Supremo Tribunal Federal". Revista Forense, vol. 208, outdez, 1964.

LIMA, Tiago Asfor Rocha. Precedentes Judiciais Civis no Brasil. São Paulo: Saraiva, 2013. LUHMANN, Niklas. Confianza. Trad. Amada Flores. Anthropos. Santiago: Universidad IberoAmericana, p. 1996.

MACCORMICK, Neil. Rethoric and the rule of law - A theory of legal reasoning. New York: Oxford University Press, 2005. 
MADOZ, Wagner Amorim. "O recurso extraordinário interposto de decisão de Juizados Especiais Federais”. Revista de Processo. São Paulo: RT, vol. 119, 2005.

MARINONI, Luiz Guilherme. "O Precedente na Dimensão da Segurança Jurídica". A Força dos Precedentes. Coord: MARINONI, Luiz Guilherme. Salvador: Editora JusPodivm, 2010.

"Uma nova realidade diante do Projeto de CPC: a ratio decidendi ou os fundamentos determinantes da decisão". Revista dos Tribunais. São Paulo: RT, vol. 918, 2012.

. Precedentes Obrigatórios. 2a ed., São Paulo: Revista dos Tribunais, 2011. MENDES, Gilmar Ferreira. "O papel do Senado Federal no controle de constitucionalidade: um caso clássico de mutação constitucional”. Revista de informação legislativa. v. 41, n. 162, abr./jun. de 2004.

NERY JÚNIOR, Nelson. "O Senado Federal e o controle concreto de constitucionalidade de leis e de atos normativos: separação de poderes, Poder Legislativo e interpretação da CF 52 X". Revista de informação legislativa. v.47, nº 187, p. 193-200, jul./set. de 2010.

NUNES, Dierle. "Processualismo constitucional democrático e o dimensionamento de técnicas para a litigiosidade repetitiva: a litigância de interesse público e as tendências 'não compreendidas’ de padronização decisória”. Revista de Processo. São Paulo: RT, vol. 189, set. 2011.

PEDRON, Flávio Quinaud. Mutação constitucional na crise do positivismo jurídico: história e crítica do conceito no marco da teoria do direito como integridade. Belo Horizonte: Arraes Editores, 2012.

SANTOS, Boaventura de Sousa. Para uma Revolução Democrática da Justiça. São Paulo: Cortez, 2007.

SOUZA, Marcelo Alves Dias de. Do precedente à sumula vinculante. Curitiba: Juruá, $1^{\mathrm{a}}$ edição (ano 2006), $2^{\mathrm{a}}$ reimpressão (ano 2013).

STRECK, Lenio Luiz; ABBOUD, Georges. O que é isto - o precedente judicial e as súmulas vinculantes?. Porto Alegre: Livraria do Advogado Editora, 2013. 
TARUFFO, Michele. "Precedente e jurisprudência". Revista de Processo. São Paulo: RT, vol. 199, 2011.

THEODORO JÚNIOR, Humberto. "Recurso especial e o novo artigo 543-C do Código de Processo Civil (Lei $\mathrm{n}^{\mathrm{o}}$ 11.672, de 08.05.08)"'. Revista Magister de Direito Civil e Processual Civil. São Paulo: Magister, nº 24, jun.-2008.

THEODORO JÚNIOR, Humberto; NUNES, Dierle José Coelho; BAHIA, Alexandre Gustavo Melo. "Breves considerações da politização do judiciário e do panorama de aplicação no direito brasileiro - Análise da convergência entre o civil law e o common law e dos problemas da padronização decisória”. Revista de Processo. vol. 189, 2010.

TUCCI, José Rogério Cruz e. Precedente judicial como fonte do direito. São Paulo: RT, 2004. 